\title{
Effect of Medium pH on In Vitro Dissolution of Marketed Tetracyclines (Tetracycline and Doxycycline) Solid Oral Dosage Forms in Bahia, Brazil
}

\author{
João Luis S. de Oliveira' ${ }^{1}$, Gilmar A. C. Teles Júnior ${ }^{1}$, Desirée A. Bonfim ${ }^{1}$, Carlos Magno R. Carvalho \\ Júnior ${ }^{1}$, Jéssica A. Santos ${ }^{1}$, Matheus S. Ferreira ${ }^{1,2}$, and Aníbal de F. Santos Júnior ${ }^{1 *}$ \\ ${ }^{1}$ Department of Life Sciences, State University of Bahia, Salvador, Bahia, Brazil. \\ ${ }^{2}$ Department of Exact and Earth Sciences, State University of Bahia, Salvador, Bahia, Brazil.
}

e-mail:afjunior@uneb.br

\section{ABSTRACT}

Tetracyclines are widely used for the treatment of infections of the lower respiratory tract and other systems. In Brazil, tetracyclines are available as generic and similar products. The aim of this study was to evaluate the in vitro release of tetracycline capsules $(500 \mathrm{mg})$ and doxycycline tablets $(100 \mathrm{mg})$ in different reaction media, from dissolution profiles, using sensitive and rapid ultraviolet spectrophotometric methods. The dissolution test was used to obtain and compare dissolution profiles and establish similarities of pharmaceutical formulations in compliance with the Brazilian (for tetracycline hydrochloride capsules) and United States (USP) (for doxycycline hydrochloride tablets) pharmacopoeia. For both drugs, the dissolution studies were conducted using an USP type 2 apparatus at $75 \mathrm{rpm}$ with $1000 \mathrm{~mL}$ distilled water at $37.0 \pm 0.5$ ㅇ $\mathrm{C}$ for 90 minutes, to evaluate the influence of $\mathrm{pH}(1.0-8.0)$ on the release of drugs. The methods were validated, showing precision, linearity, and accuracy. All the products satisfactorily released tetracycline and doxycycline, with at least $80 \%$ of the drug dissolved within 30 minutes. Tetracycline and doxycycline are weak acids, which favors their dissolution in acid media ( $\mathrm{pH}$ range 1.0-6.0). This research contributes to studies that guarantee the quality control of tetracyclines and to the expansion of the novel methodologies established by the Brazilian Pharmacopoeia for doxycycline.

KEYWORDS: Dissolution profile, tetracycline capsules, doxycycline tablets, medium pH

\section{INTRODUCTION}

B acterial infections are among the main causes of death in the world, especially in infections of the lower respiratory tract (1). Among the several useful antibiotics in its treatment, tetracyclines can be highlighted, due to their low cost, easy access and lower occurrence of adverse effects (2-5). The main drugs representing this class are tetracycline and doxycycline (Fig. 1), which have mechanisms of action explained basically by inhibiting bacterial protein synthesis, through binding to the $30 \mathrm{~S}$ subunit of the ribosomes, preventing the aminoacyl-tRNA binding (6). Recently, studies linked doxycycline as a possible drug for the treatment of Parkinson's disease, due to the inhibition of alphasynuclein aggregation, which do not evolve to fibrils, forming species with different structural arrangements that avoid the destabilization of biological membranes and the formation of additional toxic species (7-9).

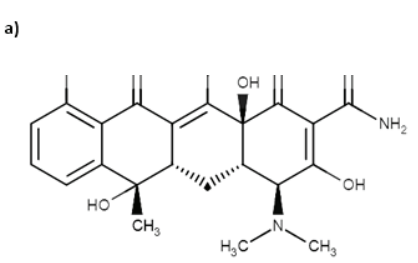

b) $\mathrm{H}_{3} \mathrm{C} \backslash \mathrm{N}-\mathrm{CH}_{3}$

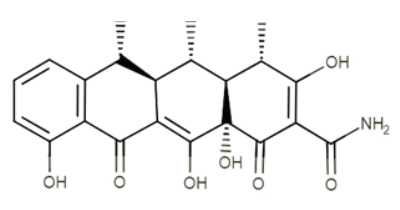

Figure 1. Molecular structures of tetracycline (a) and doxycycline (b).

In Brazil, tetracycline can be found in generic and similar specialties in the form of 500-mg capsules, and doxycycline can be found in reference, generic, and similar specialties in the form of 100-mg tablets. In addition, Brazilian health agencies require comparative studies of pharmaceutical and therapeutic equivalence with the reference drug through in vitro and in vivo tests for generic and similar drugs $(10,11)$. 
Generic products are intended to be interchangeable with a reference or innovative product and are frequently produced after the expiration or waiver of the protection patent or other exclusive rights, provided that similar effectiveness, safety, and quality are proven (12). The registration of the reference drug for tetracycline was canceled in 2012 by the National Health Surveillance Agency (ANVISA), and generic drugs were then created with the aim of improving the population's access to treatment through products with reduced prices. A "similar" drug product contains the same active pharmaceutical ingredient (API) and has the same concentration, pharmaceutical form, route of administration, posology, and therapeutic indication as the reference and generic products (13). These pharmaceutical specialties (reference, similar, and generic) differ in characteristics such as size and formulation, with a variety of excipients, and these variations may affect the dissolution kinetics of the solid oral dosage forms.

Tetracycline is an older and more hydrophilic drug and belongs to class 3 (high solubility and low permeability) of the Biopharmaceutical Classification System (BCS). Doxycycline is a more lipophilic drug (a characteristic that gives it a greater absorption and distribution capacity in the body) and belongs to BCS class 1 (high solubility and high permeability) (14). A drug must be released in the pharmaceutical form in the appropriate amount, so that the onset and duration of its action are as desired. Any factor that alters disintegration and dissolution processes of solid oral dosage forms (such as volume of the reaction medium, $\mathrm{pH}$, temperature, and oil/water partition coefficient of the compound) may directly affect their bioavailability $(3,15-19)$. In general, pharmacopoeias are official guides that indicate methodologies for quality control of medicines, in several countries. Since it is an older drug, most of these compendiums indicate tests for the physicochemical evaluation of tetracycline. The Brazilian Pharmacopoeia does not yet include methodologies for the evaluation of doxycycline solid oral dosage forms (20). To guarantee the efficacy of a product, it is important that the characteristics of the drug as well as the presence of excipients and the manufacturing techniques used are well developed, established, and controlled $(21,22)$.

In this study, analytical methodologies were developed and validated using molecular ultraviolet (UV) absorption spectrophotometry to evaluate the in vitro release of tetracycline capsules $(500 \mathrm{mg}$ ) and doxycycline tablets $(100 \mathrm{mg})$ in different reaction media from dissolution profiles, there by adding to the studies that guarantee quality control of drugs and to expansion of methodologies established by the Brazilian Pharmacopoeia for doxycycline.

\section{MATERIALS AND METHODS}

\section{Chemicals, Reagents, and Samples}

All reagents were of analytical grade. Hydrochloric acid $(\mathrm{HCl})$ was obtained from Neon Comercial (São Paulo, SP, Brazil). Boric acid $\left(\mathrm{H}_{3} \mathrm{BO}_{3}\right)$ and glacial acetic acid $\left(\mathrm{CH}_{3} \mathrm{COOH}\right)$ were obtained from Labsynth (São Paulo, SP, Brazil). The reference chemicals of tetracycline and doxycycline were obtained from Sigma-Aldrich (São Paulo, SP, Brazil) and Plantarium Pharmacy (Salvador, BA, Brazil), respectively. All labware was immersed in a $10 \%(\mathrm{v} / \mathrm{v}) \mathrm{HNO}_{3}$ solution bath for 24 hours, rinsed with high-purity water and dried at room temperature.

Distilled water was obtained from a Q341 Quimis distiller (São Paulo, SP, Brazil) and used throughout the experiments. For the preparation of all standard and sample solutions, in all analyses, ultrapure water (with resistivity $18 \mathrm{M} \Omega \mathrm{cm}^{-1}$ ) was obtained from a Milli-Q Plus water purification system (Merck Millipore, Molsheim, France). The solutions used in this study were prepared by appropriate dilution $(1.25-15.0 \mu \mathrm{g} / \mathrm{mL}$ and $2.5-30.0 \mu \mathrm{g} /$ $\mathrm{mL}$ ) and stored in decontaminated polyethylene bottles.

Generic and similar 500-mg tetracycline $\mathrm{HCl}$ capsules and 100-mg doxycycline $\mathrm{HCl}$ tablets were purchased from local pharmacies in Salvador, Bahia, Brazil. All tests were performed on products within their expiration date. Solid oral dosage forms were submitted to average weight, disintegration, and dissolution tests, following the official compendia: Brazilian Pharmacopoeia for tetracycline $\mathrm{HCl}$ capsules and United States Pharmacopeia (USP) for doxycycline $\mathrm{HCl}$ tablets (23). The characteristics of the four products as described in their drug labels:

- T1: generic tetracycline $\mathrm{HCl}$ excipients: colloidal silicon dioxide, magnesium stearate, sodium lauryl sulfate, and talc.

- T2: similar tetracycline $\mathrm{HCl}$ excipients: magnesium stearate, sodium starch glycolate, sodium lauryl sulfate, and talc.

- D1: generic doxycycline $\mathrm{HCl}$ excipients: croscarmellose sodium, microcrystalline cellulose, lactose monohydrate, magnesium stearate, hypromellose, macrogol, ethylcellulose, and titanium dioxide.

- D2: similar doxycycline $\mathrm{HCl}$ excipients: isopropyl alcohol, ethyl alcohol, copolymer of methacrylic 
acid, titanium dioxide, magnesium stearate, macrogol, povidone, mannitol, microcrystalline cellulose, and talc.

\section{Instrumentation}

The analysis of weight uniformity was performed in an electronic analytical balance (BEL Engineering, Piracicaba, SP, Brazil) and $\mathrm{pH}$ measurements were made on a pH meter (PG 2000, Gehaka, São Paulo, SP, Brazil). An Ethik Technologies (São Paulo, Brazil) disintegration test apparatus (301/AC) and dissolution test apparatus (299) multi-bath $(n=6)$ were used in accordance with the Brazilian Pharmacopoeia and the USP general methods. All spectrophotometric measurements were carried out using a Shimadzu (Kyoto, Japan) UV-Vis spectrophotometer (UV-1240, 190-1100 nm) equipped with a diode array detector. The absorbances of reference and sample solutions were read in 1-cm quartz cells. The detector was set at $276 \mathrm{~nm}$.

\section{Calibration Standards}

Stock standard solutions of tetracycline and doxycycline $(500 \mu \mathrm{g} / \mathrm{mL})$ were prepared for analysis by dissolving 25 $\mathrm{mg}$ of reference substance in a $50 \mathrm{~mL}$ volumetric flask with distilled water. For each drug, a solution with a final concentration of $50 \mu \mathrm{g} / \mathrm{mL}$ was used to obtain the standard curves $(1.25-15.0 \mu \mathrm{g} / \mathrm{mL}$ for tetracycline and $2.5-30.0 \mu \mathrm{g} / \mathrm{mL}$ for doxycycline), which were prepared daily and analyzed in triplicate by UV spectrophotometry.

\section{Dissolution Test Conditions and Kinetic Dissolution Studies}

Dissolution tests were performed in compliance with Brazilian (for tetracycline $\mathrm{HCl}$ capsules) and USP (for doxycycline $\mathrm{HCl}$ tablets) pharmacopoeia. For both drugs ( 6 capsules for tetracycline and 6 tablets for doxycycline), the dissolution studies were conducted using an apparatus 2 (paddle) at $75 \mathrm{rpm}$ with $1000 \mathrm{~mL}$ of dissolution medium (distilled water at $37.0 \pm 0.5^{\circ} \mathrm{C}$ ) for 90 minutes. All experiments were performed in triplicate. Manual sampling aliquots of $10.0 \mathrm{~mL}$ were taken at $1,3,5,10,15,20$, $30,45,60$, and 90 minutes after dissolution optimization and analyzed. The medium was replaced at $37 \pm 0.5^{\circ} \mathrm{C}$ to a constant volume. The collected aliquots were filtered and transferred to amber vials for subsequent reading at $276 \mathrm{~nm}$ in a UV-VIS spectrophotometer. The absorbance values were converted to concentration values with the standard curve equation, taking into account the amount of drug removed in each aliquot. The percentage of drug was expressed as a function of time.

In addition, a study was carried out to evaluate the influence of $\mathrm{pH}$ on the release of tetracycline and doxycycline from the oral solid dosage forms studied. Three different reaction media were tested, based on the physiological $\mathrm{pH}$ range with different $\mathrm{pH}$ values: $0.1 \mathrm{~mol} / \mathrm{L}$ $\mathrm{HCl}(\mathrm{pH} 1.0)$, sodium acetate $(\mathrm{pH} 4.5)$, distilled water $(\mathrm{pH}$ $6.0)$, and boric buffer ( $\mathrm{pH} 8.0)$. Only the generic products of each drug studied in these experiments were chosen for use, due to the greater sample availability. Dissolution test conditions (time, apparatus, and temperature) were the same as previously quoted, according to the official compendium. Collection times were simplified for tetracycline $(1,3,5,20,75$, and 90 minutes) by virtue of their rapid release from the pharmaceutical form, based on previous studies described above.

\section{Dissolution Efficiency}

One of the ways to obtain a more reliable comparison between dissolution profiles of different pharmaceutical formulas is by calculating dissolution efficiency (DE\%). This parameter was obtained from the area under the dissolution curve (ASC) of the drug up to time $(t)$ in minutes $\left(\mathrm{ASC}_{0-\mathrm{t}}\right)$, relative to $100 \%$ of the product value label $\left(\mathrm{ASC}_{\mathrm{TR}}\right.$ ) (24). DE is determined by the following equation, where $t$ is time ( $\mathrm{min}$ ) and TR is the label value of the product: $\mathrm{DE} \%=\mathrm{ASC}_{0-\mathrm{t}} / \mathrm{ASC}_{\mathrm{TR}} \times 100$.

\section{Validation of the Analytical Method}

To demonstrate the suitability of the dissolution test, it was validated following Brazilian Resolution 166/2017 (25) and International Conference on Harmonisation (ICH) guidance $(25,26)$. Thus, analyses of linearity, precision (repeatability and intermediate precision), and accuracy were performed. Possible interferences were assessed by testing the constituents (excipients) of the formulations and comparing them with a placebo.

Linearity was obtained by the correlation coefficient (evaluated by linear regression analysis using the least squares regression method) of three analytical curves with 10 different concentrations ranging from 1.25 to $15.0 \mu \mathrm{g} / \mathrm{mL}$ for tetracycline and 2.5 to $30.0 \mu \mathrm{g} /$ $\mathrm{mL}$ for doxycycline. Repeatability and intermediate precision were carried out to assess the precision of the method. Relative standard deviation (RSD) was used to calculate the precision of quantification of three known concentrations of tetracycline $(1.25,7.5$, and $12.5 \mu \mathrm{g} /$ $\mathrm{mL})$ and doxycycline $(2.5,10.0$ and $25.0 \mu \mathrm{g} / \mathrm{mL})$ on the same day and on alternate days. Accuracy was expressed as the agreement between the set reference value and the measured values of each concentration. Each concentration of tetracyclines was analyzed in triplicate, by a UV-VIS spectrophotometer. 


\section{Statistical Analysis}

A Student's t-test for paired samples and ANOVA oneway by Tukey's Multiple Comparison Test for $p$-value < 0.05 were used to compare the dissolving ability of the tetracyclines.

\section{RESULTS AND DISCUSSION}

\section{Validation of the Analytical Method}

Linearity was evaluated from the calibration curve for tetracycline with the regression equation $(y=0.0307 x-$ $0.0019)$ and determination coefficient $\left(r^{2}=0.9997\right)$ in the studied linear concentration range $(1.25-15.0 \mu \mathrm{g} / \mathrm{mL})$. For doxycycline, the regression equation $(y=0.0335 x$ $+0.0055)$ and determination coefficient $\left(r^{2}=0.9991\right)$ were obtained, in the studied linear concentration range $(2.5-30 \mu \mathrm{g} / \mathrm{mL})$. The quantity of drug dissolved, in each sample, was calculated from these equations. The values for precision (repeatability and intermediate precision) and accuracy of the analytical method are shown in Table 1.

Table 1. Evaluation of Precision (Repeatability and Intermediate Precision) and Accuracy

\begin{tabular}{|c|c|c|c|}
\hline \multirow[t]{2}{*}{ Sample } & \multirow{2}{*}{$\begin{array}{l}\text { Theoretical } \\
\text { Concentration } \\
(\mu \mathrm{g} / \mathrm{mL})\end{array}$} & RSD (\%) & \multirow[t]{2}{*}{ Accuracy (\%) } \\
\hline & & $\begin{array}{l}\text { Repeatability; } \\
\text { Intermediate }\end{array}$ & \\
\hline \multirow[t]{3}{*}{ Tetracycline } & 1.25 & $5.76 ; 2.85$ & 95.9 \\
\hline & 7.5 & $4.59 ; 0.22$ & 101.7 \\
\hline & 12.5 & $0.91 ; 0.52$ & 99.7 \\
\hline \multirow[t]{3}{*}{ Doxycycline } & 2.5 & $6.64 ; 1.88$ & 98.9 \\
\hline & 10.0 & $1.94 ; 0.42$ & 97.6 \\
\hline & 25.0 & $0.69 ; 0.17$ & 98.7 \\
\hline
\end{tabular}

$R S D$, Relative standard deviation.

Precision was obtained on the same day (intra-day) and alternate days (inter-days) for the UV spectrophotometric method under standard conditions of dissolution tests. RSD values below $10 \%$ were obtained; therefore, the proposed method was considered satisfactory, according to Anvisa Resolution 166/2017 and ICH. Accuracy was expressed as a percentage of the agreement between the set reference value and the measured value of each concentration, in triplicate in a UV-VIS spectrophotometer at $276 \mathrm{~nm}$. The mean recovery obtained ranged from $95.9 \%$ to $101.7 \%$. There was no interference from matrix components. The proposed method proved to be advantageous as it is economical, easy to apply, has good analytical frequency and robustness, and is useful for quality control of tetracycline products.

\section{Formulation Composition, Weight Uniformity, and Disintegration Tests}

Excipients that make oral solid dosage forms may have a direct influence on disintegration and dissolution processes (27). Capsule formulations containing tetracycline basically had the same excipients; however, it was observed that product $\mathrm{T} 2$ (similar) contains sodium starch glycollate, a disintegrating agent, which facilitates wettability of the pharmaceutical form, leading to rapid disintegration. In addition, sodium starch glycollate has the advantage of not having its efficiency affected by the presence of hydrophobic excipients, such as lubricants. For the doxycycline-containing tablets, the composition of products D1 (generic) and D2 (similar) was quite varied. Product D1 contains ethylcellulose (as a possible coating agent), which has a hydrophobic character and may delay the release of the drug from the tablet. It was observed that product D2 contains a copolymer of methacrylic acid, a coating agent which generally favors dissolution of the tablet in solutions with $\mathrm{pH}$ above 5.5 , such as the upper intestine (28).

Weight uniformity is a test that allows to evaluate the homogeneity of the weight of the units of each lot, as well as to obtain an indirect prediction of dose uniformity, since the formulas are based on the weight of the pharmaceutical forms, which will also influence the concentration of active principles in each unit (19). The results showed that weight values varied for tetracycline ( $\mathrm{T} 1$ and $\mathrm{T} 2: 513.1 \pm 3.45$ and $538.3 \pm 3.26 \mathrm{mg}$, respectively) and doxycycline (D1 and D2: $370.1 \pm 2.10$ and $248.8 \pm$ $1.76 \mathrm{mg}$, respectively) and have satisfactory averages, according to the Brazilian Pharmacopoeia (for hard capsules weighing $500 \mathrm{mg}$ and tablets containing $100 \mathrm{mg}$ of the drug, the allowable variation range is $\pm 7.5 \%$ ) (20). Small differences in weight between the formulations of each medicament were observed, which may, for example, be related to a greater amount or proportion of excipients (29).

All formulations met the official compendium requirements for tablets (disintegration time $<30$ minutes for tablets and $<45$ minutes for capsules). The differences observed may be associated to the different disintegrating agents used in the formulations of the analyzed products. In addition, for the tablets, the production process and the compression force used may have an influence (i.e., the greater the force used, the longer the disintegration time) (30). 


\section{Dissolution Test, Dissolution Profiles, and Dissolution Efficiency (DE)}

The Brazilian Pharmacopoeia recommends that not less than $80 \%$ of the tetracycline label amount $(500 \mathrm{mg})$ must dissolve within 90 minutes. For doxycycline tablets, the USP recommends that not less than $85 \%$ of doxycycline label amount (100 mg) must dissolve, also within 90 minutes. For the dissolution tests of the solid oral pharmaceutical forms, the results were in accordance with the pharmacopoeias.

Several factors may affect dissolution results, such as the nature of the excipients used and the disintegration rate. In general, intestinal absorption of drugs from solid oral dosage forms is associated with four main factors: available surface area, intestinal transit, membrane permeability, and drug concentration profile by time in the lumen (31). Therefore, the dissolution test functions as a predictor of the solubility behavior of the drug in the chosen medium (in vitro), so that it is available to be absorbed, in a suitable time and, to have therapeutic effect. Also, from its results, it allows the interchangeability between different products, as reference, generic, and similar $(32,33)$. Multipoint analysis graphs were plotted (Fig. 2) to evaluate the percentage of drugs, across dissolution profiles for tetracycline capsules (500 mg) and doxycycline tablets (100 mg).

All capsules (generic and similar) containing tetracycline (500 mg) dissolved in accordance with the Brazilian Pharmacopoeia recommendations ( $>80 \%$ of drug within 30 minutes). T1 and T2 products showed comparable levels of drug release within the time range $(106.26 \%$ and $104.38 \%$ of the dissolved tetracycline in the dissolution media at 90 minutes). It was observed that T1 had a dissolution rate slightly faster than $\mathrm{T} 2$, and in less than 10 minutes the samples had already released almost all the drug. This observation can be explained by the fact that tetracycline is a BCS class 3 drug. Although the similar product contains sodium starch glycollate (disintegrant) in its formulation, the delay of its disintegration and the release of the drug from the generic can be attributed to the differences between the casing of capsules of different manufacturers. The results of this study are consistent with Fahmy et al., who showed that, at 10 minutes, tetracycline boluses had already released $100 \%$ of the drug (34).

Narkhede et al. conducted a study on the dissolution of tetracycline $\mathrm{HCl}$ microcapsules developed with ethylcellulose polymer for sustained release (35). The authors observed that some formulations reached about $100 \%$ of the drug release in 8 hours, which shows that, although tetracycline is a very soluble class $3 \mathrm{drug}$, the use of hydrophobic substances in the formulation may delay the dissolution of medicaments containing this drug (35).

Dissolution profiles of generic and similar doxycycline (100 mg) tablets showed similar behavior, in accordance with the USP recommendations ( $>85 \%$ of drug within 90 minutes). Initially, D2 showed the release of the drug at a slightly higher rate when compared to D1. This fact may be related to the formulation of these products, due to the presence of povidone in the similar product, which acts as a disintegrant, favoring the dissolution process $(28,35)$. In addition, the generic product has higher average weight and a greater amount of excipients, which results in longer disintegration and dissolution times. Although D1 has croscarmellose sodium (disintegrating
A

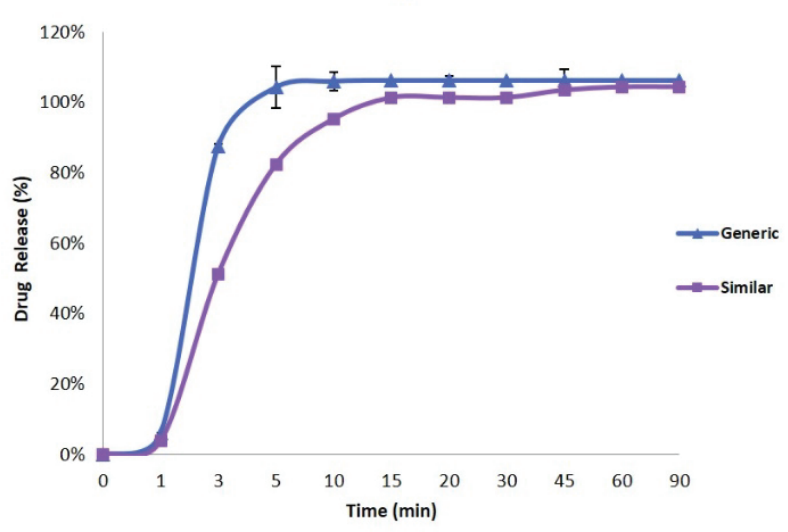

B

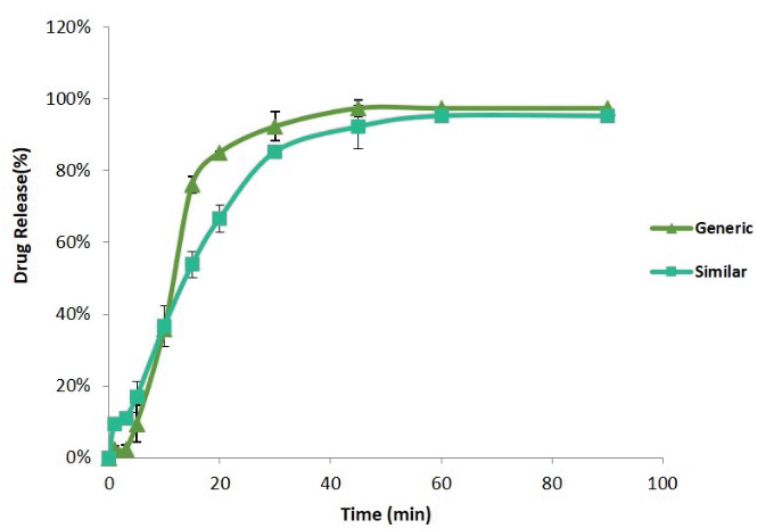

Figure 2. Comparative dissolution profiles of 500-mg tetracycline capsules (A) and 100-mg doxycycline tablets (B) by USP type 2 apparatus at $75 \mathrm{rpm}$ with $1000 \mathrm{~mL}$ distilled water at $37.0 \pm 0.5^{\circ} \mathrm{C}$ for $90 \mathrm{~min}$. 
agent), it contains ethylcellulose (coating agent), which can delay the disintegration and release of the drug in aqueous medium due to its hydrophobic character. The data obtained in this study are concordant with Aguiar et al., who evaluated the dissolution kinetics of doxycycline tablets and reported that, in about 30 minutes, all products had already released $80 \%$ of the drug (36). Shah et al. produced and evaluated the dissolution profile of doxycycline hydrochloride gelatin capsules and demonstrated that, in less than 5 minutes, all products released more than $70 \%$ of the drug. In that case, the pharmaceutical form influenced the rapid release of the drug (37).

DE values were calculated, as a comparison tool of the dissolution profiles. DE is a variable related to the real amount of drug that is dissolved in the medium (38, 39). DE values for tetracycline capsules (500 mg) and doxycycline tablets $(100 \mathrm{mg}$ ) were $98.6 \%$ and $78.5 \%$ for similar (T1 and D1, respectively) and $103.5 \%$ and $82.9 \%$ for generic products (T2 and D2, respectively). These data demonstrate that generic drugs showed better dissolution performance compared to similar drugs. In a study conducted by Aguiar et al., the DE of doxycycline reference drugs presented results of $77.33 \%$ and $78.39 \%$, and these values were close to those obtained for the generic drugs in this study (36). No data were found in the literature concerning DE of solid pharmaceutical forms containing tetracycline.

In Brazil, ANVISA Resolution 31/2010 provides for the necessary requirements for pharmaceutical equivalence and comparative dissolution profile studies (10). The results showed a very rapid dissolution (> 85\% drug release) in 15 minutes for Tetracycline and, according to ANVISA Resolution 31/2010, in Brazil, the calculations of $f_{1}$ and $f_{2}$ are not necessary. For Doxycycline, comparative dissolution profiles were only evaluated using the similarity factor $\left(f_{2}\right)$. The calculation for doxycycline comparison was performed according to the equation below, where $\mathrm{n}$ is the number of collection times considered for the calculation of $f_{2} ; R_{t}$ is the percentage value dissolved at time $t$ obtained with the comparator drug (generic); and $T_{t}$ is the dissolved percentage value of test drug (similar) at time $t$.

$$
F 2=50 \times \log \left\{\left[1+\left(\frac{1}{n}\right) \sum_{t=1}^{n}(R t-T t)^{2}\right]^{-0,5} \times 100\right\}
$$

The $f_{2}$ value obtained for doxycycline was 55.5. This result shows that the dissolution profiles of D1 and D2 are similar, since the value is between 50 and 100, according to the criterion established by ANVISA Resolution 31/2010 (10).

The rate-limiting step of drug absorption from the gastrointestinal tract is frequently dissolution from the dosage form (40). Factors related to the drug, production technology, and the reaction medium influence this process. The physiological $\mathrm{pH}$ is a limiting factor for the release and dissolution of the drug in the biological fluids and, consequently, for its absorption $(27,30)$. In this study, the investigation of other means of dissolution was proposed, aiming to expand the studies about the behavior of the release of tetracyclines (tetracycline and doxycycline) in other reactional media from the oral solid dosage forms, in addition to contributing with the Brazilian Pharmacopoeia, which does not present methodology for dissolution tests for doxycycline. The influence of $\mathrm{pH}$ on the release of tetracyclines from capsules and tablets (generic products) was studied in four different reaction media, based on the physiological $\mathrm{pH}$ range with different $\mathrm{pH}$ values (1.0; 4.5; 6.0, and 8.0). Regarding the influence of $\mathrm{pH}$ on the dissolution of tetracycline and doxycycline, the obtained data agreed with the literature, indicating that this drug has a higher solubility in water and in acidic medium (Fig. 3).

Tetracycline is a weak acid (pKa 3.3), which favors its dissolution in acid media (41). After 20 minutes, more than $80 \%$ of the drug was released, regardless of the $\mathrm{pH}$ value of the medium. This suggests that its greatest absorption will be in the stomach and in some parts of the small intestine, such as the duodenum. In other regions, as in the jejunum, the solubility and, consequently, its absorption may be reduced $(42,43)$. For doxycycline (pKa $=3.5)$, the same behavior of tetracycline was observed. However, in basic $\mathrm{pH}$ there was no change in solubility and dissolution profiles in the different reaction media. Doxycycline is a more lipophilic drug and belongs to class 1 (high solubility and high permeability) of BCS $(14,43)$. After 30 minutes, more than $85 \%$ of the drug was released, regardless of the $\mathrm{pH}$ value of the medium. The study of the dissolution behavior of tetracyclines at different $\mathrm{pH}$ values can mimic conditions for dissolution in the gastrointestinal tract.

\section{CONCLUSION}

Biopharmaceutical studies are essential to ensure the quality control of solid oral dosage forms, as well as providing information that contributes to better management of drugs, from manufacturing to clinical use. 
A

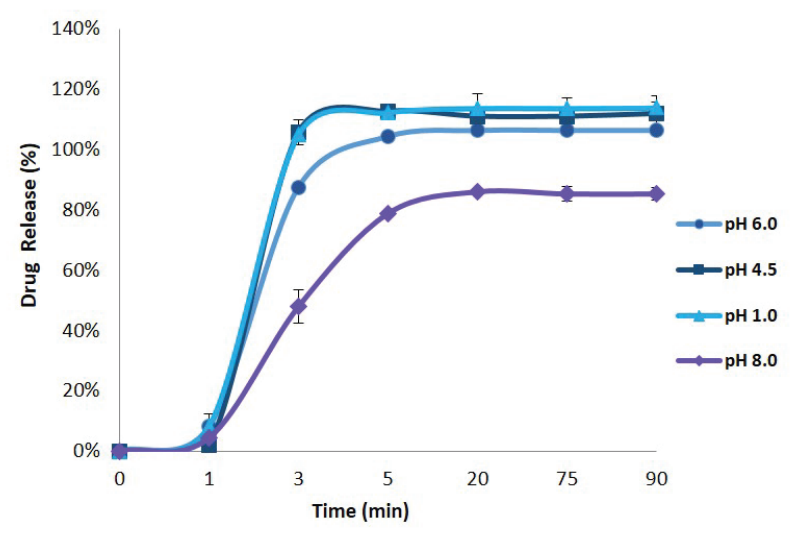

B

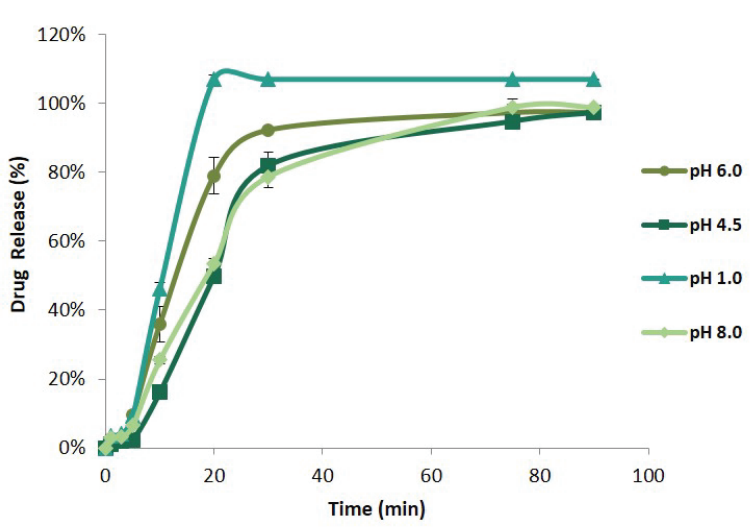

Figure 3. Comparative dissolution profiles of generic 500-mg tetracycline capsules (A) and 100-mg doxycycline tablets (B) in different $\mathrm{pH}$ solutions by USP type 2 apparatus at $75 \mathrm{rpm}$ with $1000 \mathrm{~mL}$ solution at $37.0 \pm 0.5^{\circ} \mathrm{C}$ for $90 \mathrm{~min}$.

The results showed that both drugs studied, tetracycline and doxycycline, are in accordance with the specifications recommended by the Brazilian Pharmacopoeia and USP for weight uniformity, disintegration, and dissolution. Tetracycline samples (generic and similar products) were analyzed using a validated UV spectrophotometric method. Minor differences observed in the evaluation of dissolution kinetics showed that the excipients, as well as the industrial processes, can influence test results.

Drug release was satisfactory for all products, because at least $>80 \%$ of drugs were dissolved in the medium within 90 minutes. The release of tetracycline is influenced by the $\mathrm{pH}$ of the medium, demonstrating reduced basic conditions. The dissolution test for doxycycline was validated to contribute to the Brazilian Pharmacopeia. Therefore, it was observed that it is possible to use dissolution tests for quality control of tetracyclines including doxycycline.

\section{ACKNOWLEDGEMENTS}

The authors are grateful for the financial support received from Bahia State Research Support Foundation and collaborations of the State University of Bahia and the Biopharmaceutics and Drugs Research Group.

\section{CONFLICTS OF INTEREST}

The authors declare that there are no conflicts of interest regarding this article.

\section{REFERENCES}

1. World Health Organization website. Global Health Estimates 2016: Deaths by Cause, Age, Sex, by Country and by Region, 2000-2016. Geneva: World Health Organization, 2018. https:// www.who.int/healthinfo/global_burden_disease/estimates/ en/index1.html (accessed Apr 25, 2019).
2. Chopra, I.; Roberts, M. Tetracycline antibiotics: mode of action, applications, molecular biology, and epidemiology of bacterial resistance. Microbiol. Mol. Biol. Rev. 2001, 65, 232-260. DOI: 10.1128/MMBR.65.2.232-260.2001.

3. Wong, T.; Singh, A. E.; De, P. Primary Syphilis: Serological treatment response to doxycycline/tetracycline versus benzathine penicillin. Am. J. Med. 2008, 121, 903-908. DOI: 10.1016/j.amjmed.2008.04.042.

4. Novacco, M.; Sugiarto, S.; Willi, B.; Baumann, J.; Spiri, A.M.; Oestmann, A.; Riond, B; Boretti, F.; Naegeli, H.; HofmannLehmann, R. Consecutive antibiotic treatment with doxycycline and marbofloxacin clears bacteremia in Mycoplasma haemofelis-infected cats. Vet. Microbiol. 2018, 217, 112-120. DOI: 10.1016/j.vetmic.2018.03.006.

5. Cunha, B. A. Oral doxycycline for non-systemic urinary tract infections (UTIs) due to P. aeruginosa and other Gram negative uropathogens. Eur. J. Clin. Microbiol. Infect. Dis. 2012, 31, 28652868. DOI: 10.1007/s10096-012-1680-0.

6. Guimarães, D. O.; Momesso, L. S.; Pupo, M. T. Antibiotics: therapeutic importance and perspectives for the discovery and development of new agents. Quim. Nova. 2010, 33, 667-679. DOI: 10.1590/S0100-40422010000300035.

7. González-Lizárraga, F.; Socías, S. B.; Ávila, C. L.; Torres-Bugeau, C. M.; Barbosa, L. R. S.; Binolfi, A.; Sepúlveda-Díaz, J. E.; Del-Bel, E.; Fernandez, C. O.; Papy-Garcia, D.; Itri, R.; Raisman-Vozari, R.; Chehín, R. N. Repurposing doxycycline for synucleinopathies: remodelling of $\alpha$-synuclein oligomers towards non-toxic parallel beta-sheet structured species. Sci. Rep. 2017, 7, 41755. DOI: 10.1038/srep41755.

8. Bortolanza, M., Nascimento, G. C.; Socias, S. B.; Ploper, D.; Chehín, R. N.; Raisman-Vozari, R.; Del-Bel E. Tetracycline repurposing in neurodegeneration: focus on Parkinson's disease. J. Neural. Transm. 2018, 125, 1403-1415. DOI: 10.1007/ s00702-018-1913-1.

9. Lazzarini M.; Martin, S.; Mitkovski, M.; Vozari, R. R.; Stühmer, W.; Bel E. D. Doxycycline restrains glia and confers neuroprotection 
in a 6-OHDA Parkinson model. Glia. 2013, 61, 1084-100. DOI: 10.1002/glia.22496.

10. Resolution of the Board of Directors - RDC No. 31. Ministry of Health, Brazilian Health Surveillance Agency (ANVISA): Brasília, August 11, 2010. http://portal.anvisa. gov.br/documents/33880/2568070/rdc0037_03_08_2011. pdf/13c41657-e93b-4d09-99eb-377f760f3aa0 (accessed Apr 23, 2019).

11. Resolution of the Board of Directors - RDC No. 16. Ministry of Health, Brazilian Health Surveillance Agency (ANVISA): Brasília, March 02, 2007. http://bvsms.saude.gov.br/bvs/saudelegis/ anvisa/2007/rdc0016_02_03_2007.html. (accessed April 23, 2019).

12. Resolution of the Board of Directors - RDC No. 60. Ministry of Health, Brazilian Health Surveillance Agency (ANVISA): Brasília, October 10, 2014. https://www20.anvisa.gov.br/coifa/pdf/ rdc60.pdf (accessed Apr 3, 2019).

13. Concepts and Definitions of Medicines. Brazilian Health Surveillance Agency (ANVISA): Brasília, 2011. http://portal. anvisa.gov.br/medicamentos/conceitos-e-definicoes (accessed May 3, 2019).

14. Custodio, J. M.; Wu, C.; Benet, L. Z. Predicting drug disposition, absorption/elimination/transporter interplay and the role of food on drug absorption. Adv. Drug Deliv. Rev. 2008, 60, 717733. DOI: 10.1016/j.addr.2007.08.043.

15. Uebbing, L.; Klumpp, L.; Webster, G. K.; Löbenberg, R. Justification of disintegration testing beyond current FDA criteria using in vitro and in silico models. Drug Des. Devel. Ther. 2017, 11, 1163-1174. DOI: 10.2147/DDDT.S131213.

16. Souza, J.; Freitas, Z. M. F.; Storpirtis, S. In vitro models for the determination of drug absorption and a prediction of dissolution/absorption relationships. Rev. Bras. Cienc. Farm. 2007, 43, 515-527. DOI: 10.1590/S1516-93322007000400004.

17. Silva, R. L.; Volpato, N. M. Media for nimesulide tablet dissolution: surfactant action. Braz. J. Pharm. Sci. 2002, 38, 163-172. DOI: 10.1590/S1516-93322002000200005.

18. Dissolution Testing of Immediate Release Solid Oral Dosage Forms; Guidance for Industry; U.S. Department of Health and Human Services, Food and Drug Administration, Center for Drug Evaluation and Research (CDER), U.S. Government Printing Office: Washington, DC, 1997.

19. Anand, O.; Yu, L. X.; Conner, D. P.; Davit, B. M. Dissolution testing for generic drugs: an FDA perspective. AAPS J. 2011, 13, 328335. DOI: 10.1208/s12248-011-9272-y.

20. Brazilian Pharmacopeia, 5th ed.; Brasília: Brazilian Health Surveillance Agency; 2010.

21. Ansel, H. C.; Popovich, N. G.; Allen, L. V. Pharmaceutical Forms and Drug Delivery Systems, 9th ed; Artes Médicas: Porto Alegre, 2013; pp 35-45.

22. Santos Júnior, A. F.; Barbosa, I. S.; Santos, V. L.; Silva, R. L.; Caetite Júnior, E. Test of dissolution and comparison of in vitro dissolution profiles of coated ranitidine tablets marketed in
Bahia, Brazil. Braz. J. Pharm. Sci. 2014, 50, 83-89. DOI: 10.1590/ S1984-82502011000100008.

23. The United States Pharmacopeia and National Formulary USP 41-NF 36; The United States Pharmacopeial Convention, Inc.: Rockville, MD, 2018. DOI: 10.4135/9781412963855.n1200.

24. Khan, K. A. The concept of dissolution efficiency. J. Pharm. Pharmacol. 1975, 27, 48-49. DOI: 10.1111/j.2042-7158.1975. tb09378.x.

25. Resolution of the Board of Directors - RDC No. 166. Ministry of Health, Brazilian Health Surveillance Agency (ANVISA): Brasília, July 24, 2017. https://www20.anvisa.gov.br/coifa/pdf/rdc166. pdf (accessed Apr 3, 2019).

26. International Conference on Harmonisation of Technical Requirements for Registration of Pharmaceuticals for Human Use. Validation of Analytical Procedures: Text and Methodology Q2(R1); ICH Harmonised Tripartite Guideline: Geneva, Switzerland, 2005. DOI: 10.1002/9781118971147.ch5.

27. Aulton, M. E. Design of Pharmaceutical Forms, 2th ed; Artes Médicas: Porto Alegre, 2005; pp 402-466.

28. Rowe, R. C.; Sheskey, P. J.; Quinn, M. E. Handbook of Pharmaceutical Excipients, 6th ed; Pharmaceutical Press: London, 2009; pp 1-917.

29. Markl, D.; Zeitler, J. A. A review of disintegration mechanisms and measurement techniques. Pharm. Res. 2017, 34, 890-917. DOI: 10.1007/s11095-017-2129-z.

30. Storpirtis, S.; Gonçalves, J. E.; Chiann, C.; Gai, M. N. Biopharmacotechnics, Guanabara Koogan: Rio de Janeiro, 2011; pp 35.

31. Barreiro, E. J.; Fraga, C. A. M. Medicinal Chemistry: the Molecular Bases of Drug Action, 2th ed; Artes Médicas: Porto Alegre, 2008; pp 28-42.

32. Silva, R. L.; Souza, R. S.; Teles, A. L. B.; Santos Júnior, A. F.; Branco, C. R. C.; Santos Júnior, M. C. Comparative in vitro analysis of dissolution profiles of pharmaceutical formulations containing amoxicillin. Lat. Am. J. Pharm. 2013, 32, 358-363.

33. Banakar, U. V. Pharmaceutical Dissolution Testing, Marcel Dekker: New York, 1992; pp 437.

34. Fahmy, R.; Marnane, W.; Bensley Jr, D.; Hollenbeck, R. G. Dissolution testing of veterinary products. Dissolution Technol. 2001, 8, 1-3. DOI: 10.14227/DT080101P8.

35. Narkhede, P. S.; Umarkar, A. R.; Patil, P. P.; Patill, P. V. Formulation and evaluation of tetracycline hydrochloride microcapsules by solvent evaporation method. Int. J. Pharma. Bio. Sci. 2011, 1, 372-376.

36. Aguiar, G.; Faria, L. G.; Ferraz, H. G.; Serra, C. H. R.; Porta, V. In vitro biopharmaceutical evaluation of solid dosage forms containing doxycycline. Rev. Bras. Cienc. Farm. 2005, 41, 451-458. DOI: 10.1590/S1516-93322005000400007.

37. Shah, S. N. H.; Aslam, S.; Javed, H.; Nawaz, A.; Kamboh, K.; Javaid, M. M. Formulation and evaluation of taste masked doxycycline $\mathrm{HCl}$ medicated jelly. Der Pharmacia Sinica. 2017, 8, 33-39.

38. Ogochukwu, U.; Christianah, I.; Marlene, E.; Sabinus, O.; Martins, 
E. Quality assessment of some brands of clarithromycin and azithromycin tablets using the concept of dissolution efficiency and similarity factor. IJPSR. 2018, 9, 5401-5410. DOI: 10.13040/ IJPSR.0975-8232.9(12).5401-10.

39. Conceição, A. P.; Sá, R. R.; Silva, V. C.; Ferreira, M. S.; Cazedey, E. C. L.; Magalhães, H. I. F.; Santos Júnior, A. F. A comparative study of propranolol release by in vitro dissolution profiles in pharmaceutical formulations. Dissolution Technol. 2018, 25, 54-61. DOI: 10.14227/DT250418P54.

40. Hörter, D.; Dressman, J. B. Influence of physicochemical properties on dissolution of drugs in the gastrointestinal tract.
Adv. Drug Deliv. Rev. 1997, 25, 3-14. DOI: 10.1016/S0169409X(96)00487-5.

41. Serjeant, E. P.; Dempsey, B. Ionisation Constants of Organic Acids in Aqueous Solution, Pergamon Press: New York, 1979; pp 989.

42. Silva, P. Pharmacology, 8th ed.; Guanabara Koogan: Rio de Janeiro, 2010; pp 44-53.

43. Agwuh, K. N.; Macgowan, A. Pharmacokinetics and pharmacodynamics of the tetracyclines including glycylcyclines. J. Antimicrob. Chemother. 2006, 58, 256-265. DOI: 10.1093/jac/ dkl224. 